\title{
Development and Validation of a Simple and Sensitive Spectrometric Method for Estimation of Cisplatin Hydrochloride in Tablet Dosage Forms: Application to Dissolution Studies
}

\author{
Mohit Basotra, Sachin Kumar Singh, and Monica Gulati \\ School of Pharmaceutical Sciences, Lovely Professional University, Phagwara, Punjab 144411, India \\ Correspondence should be addressed to Monica Gulati; monicagulati14@gmail.com
}

Received 2 July 2013; Accepted 11 August 2013

Academic Editors: J. N. Latosinska, E. Lodyga-Chruscinska, S. Materazzi, T. Michalowski, and X. Zeng

Copyright (c) 2013 Mohit Basotra et al. This is an open access article distributed under the Creative Commons Attribution License, which permits unrestricted use, distribution, and reproduction in any medium, provided the original work is properly cited.

Cisplatin hydrochloride is an important chemotherapeutic drug for cancer treatment. It has a low molar absorptivity in the UV region and has no fluorescence. Therefore, a selective derivatizing reaction is required for its detection in bulk and pharmaceutical dosage form if detection by UV spectrophotometry is sought. In view of this, a simple, accurate, rapid, and cost-effective spectrophotometric method for its estimation has been developed by the complexation of the drug with ortho-phenylene diamine and monitoring the absorbance of formed green color at $706 \mathrm{~nm}$. The method has been validated and successfully applied for the assay and dissolution studies of cisplatin hydrochloride tablets. The method demonstrated good linearity over the range from 0.4 to $1.4 \mu \mathrm{g} / \mathrm{mL}$ with a correlation coefficient of 0.9999 . The accuracy of the method was $99.98 \%$. The precision demonstrated relative standard deviation of less than $2.5 \%$. The developed method was successfully applied for dissolution studies of sustained release tablets of cisplatin with a cumulative release of $86.7 \%$ in 12 hours. The proposed method can be applied in routine quality control in the pharmaceutical industries since it is precise, accurate, simple, and economic.

\section{Introduction}

Cisplatin is an important chemotherapeutic drug for cancer treatment since 1978. It is one of the complexes responsible for cell division inhibition phenomenon [1]. In order to evaluate the drug in pharmaceutical dosage forms and in clinical situations and to optimize therapeutic regimens, analytical methods capable of separating the drug from its excipients or from its individual biotransformation products and detecting these species at therapeutically relevant levels are required [2]. Several efforts have been made so far that include derivative spectrophotometry [3-6], detection by phosphorescence of cisplatin in urine and plasma [7], atomic absorption spectrometry [8-10], electroanalytical methods [11], and highperformance liquid chromatography methods [12-21]. The structure of cisplatin hydrochloride is shown in Figure 1.

Cisplatin has a low molar absorptivity in the UV region and has no fluorescence. Therefore, a selective derivatizing reaction is required for the detection of drug in biological samples if the optical detection is sought. In view of this several derivatization methods have been developed but suffered from some limitations. Johnson et al. determined cisplatin in urine using derivative spectrophotometry. This method has some disadvantages as the derivatizing reaction was completed in $24 \mathrm{~h}$ and the reagent cannot be found easily in the market [3]. Anilanmert et al. [4] presented a method for quantification of cisplatin by complexing cisplatin with $o$-phenylenediamine (OPDA). The product was obtained at $\mathrm{pH} 6.2$, in $30 \mathrm{~min}$ at $90^{\circ} \mathrm{C}$, giving a maximum absorbance at $705 \mathrm{~nm}$. The method was found specific for formed complex, and the maximum absorbance at $705 \mathrm{~nm}$ was far beyond the wavelengths of the absorption of cisplatin, $o$-phenylenediamine, and biomolecules in the urine. The detection limit of cisplatin in spiked urine sample was $8.40 \mu \mathrm{g} / \mathrm{mL}$. The basic limitation of this method includes its higher detection limit, and the method needed to be validated. Khuhawar et al. [5] developed the spectrophotometric determination of platinum (II) from platinum-based cisplatin and carboplatin injections. In the present study platinum was treated with bis(2-hydroxynaphthaldehyde) ethylenediamine $\left(\mathrm{H}_{2} \mathrm{HN}_{2} \mathrm{en}\right)$ 


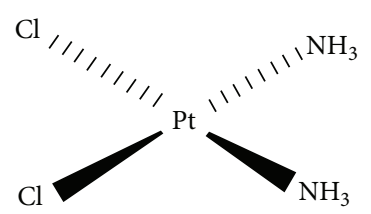

FIGURE 1: Chemical structure of cisplatin.

in presence of methanol at $\mathrm{pH}$. The mixture was heated on water bath for 15 minutes at $70-75^{\circ} \mathrm{C}$. The contents were allowed to cool and were transferred to separating funnel. Further the drug was extracted using chloroform, and the chloroform extract containing cisplatin was estimated at $355 \mathrm{~nm}$. The major limitation of this method was the preparation of $\mathrm{H}_{2} \mathrm{HN}_{2}$ en (prepared by condensation of 2hydroxynaphthaldehyde with ethylenediamine in 2:1 molar ratio in ethanol), because this reagent is not easily available in market; the second limitation of this method is the use of multistep processes to extract out platinum followed by quantification. The extraction step may lead to inaccuracy in the quantification of drug as one has to take serious care during extraction of platinum from cisplatin. If the extraction would not be complete then it would produce error in the results; the third limitation of this method includes the need of its validation.

Edward et al. [6] also developed the method for the estimation of platinum (IV or II) by using derivatization technique with the help of $o$-phenylenediamine (OPDA). In this study platinum solution was treated with OPDA in presence of dimethylformamide (DMF) at $\mathrm{pH}$ 6.5. The solution was heated on boiling water bath for $4 \mathrm{~min}$, and the developed light blue color of platinum-OPDA complex was detected at $703 \mathrm{~nm}$ against water as blank. This method was basically used to check the effect of $\mathrm{pH}$ and temperature on formation of complex and to find out the purity of platinum. Moreover, the method was needed to be validated for the desired purpose.

Most of the methods mentioned above were utilized for the clinical investigation of cisplatin, and thus the need of developing a simple, rapid, sensitive, cost-effective, and robust method is sought to quantify the drug during its regular quality control testing (e.g., assay and dissolution) and to fulfill batch release specifications.

In the present study we have used the principle of formation of complex of platinum with OPDA as used by Edward et al., to estimate the amount of cisplatin hydrochloride present in tablet dosage form. The developed method was validated as per ICH $Q_{2}\left(R_{1}\right)$ guidelines and successfully applied for assay and dissolution studies of cisplatin hydrochloride. The basic chemical reaction involved in the complex formation is shown in Figure 2.

\section{Experimental}

2.1. Materials. Cisplatin hydrochloride was obtained as a gift sample from Astron Research Limited, Gujarat, India.

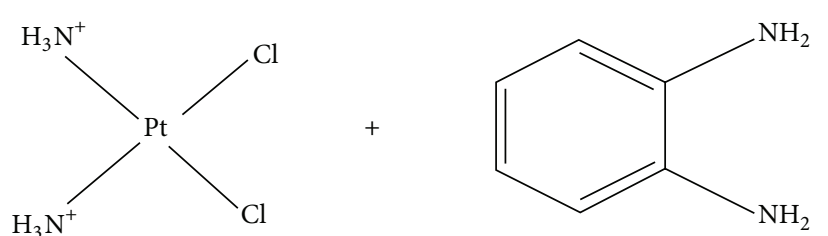

Cisplatin
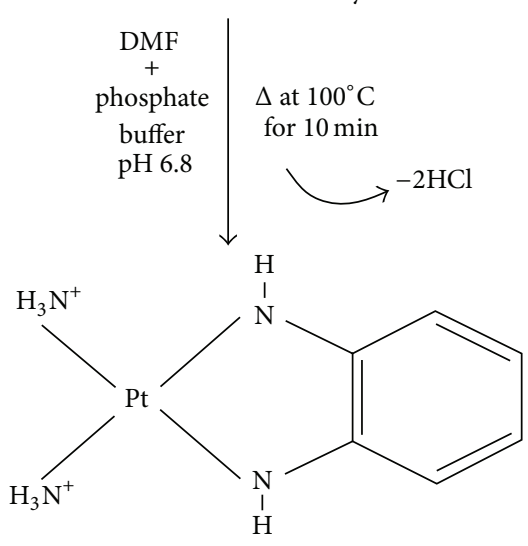

Cisplatin $+o$-Phenylenediamine

Green colour complex

FIgURE 2: Reaction between cisplatin and $o$-phenylenediamine.

$o$-Phenylenediamine and potassium dihydrogen orthophosphate were purchased from $\mathrm{CDH}$ Laboratories, Mumbai, India. Dimethylformamide (DMF) was purchased from Loba Chemie Pvt. Ltd., Mumbai, India. Sodium hydroxide flakes were purchased from Loba Chemie, Mumbai, India. All other chemicals and reagents used were of analytical grade. Triple distilled water was used throughout the study. Analysis was done using double beam UV-Visible spectrophotometer (Shimadzu 1800, Japan).

\subsection{Methods}

2.2.1. Spectrophotometric Measurements. The spectra of different concentrations of reference solutions of Cisplatin hydrochloride were recorded in $1 \mathrm{~cm}$ glass cells at a fast scan speed. The spectrophotometric measurements were recorded by using mixture of $1.4 \mathrm{mg} / \mathrm{mL}$ of OPDA solution, phosphate buffer $\mathrm{pH}$ 6.8, and DMF $(1: 2: 7)$ as a blank solution as shown in Figure 3.

\subsubsection{Analytical Method Development}

(1) Development of Colour and Preparation of Calibration Curve. Ten milligrams of cisplatin hydrochloride working standard was weighed accurately and transferred to $100 \mathrm{~mL}$ standard volumetric flask, and the volume was adjusted to $100 \mathrm{~mL}$ using phosphate buffer $\mathrm{pH} 6.8$ in order to get a concentration of $100 \mu \mathrm{g} / \mathrm{mL}$. $10 \mathrm{~mL}$ of sample aliquot was withdrawn from this stock solution and was diluted to obtain the known standard concentration of $10 \mu \mathrm{g} / \mathrm{mL}$. From this, $0.4,0.6,0.8,1.0,1.2$, and $1.4 \mathrm{~mL}$ of aliquots were withdrawn in 


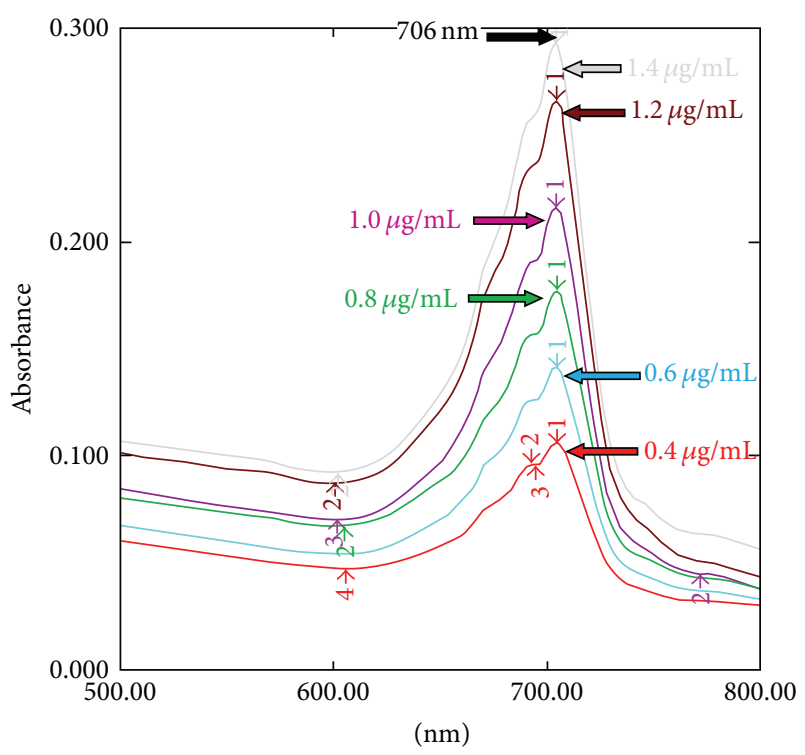

FIGURE 3: Spectrum of different concentrations of cisplatin hydrochloride in a mixture of $1.4 \mathrm{mg} / \mathrm{mL}$ of OPDA solution, phosphate buffer $\mathrm{pH}$ 6.8, and DMF.

$10 \mathrm{~mL}$ standard volumetric flask, and then $1 \mathrm{~mL}$ of $1.4 \mathrm{mg} / \mathrm{mL}$ of OPDA solution and $2 \mathrm{~mL}$ of phosphate buffer $\mathrm{pH} 6.8$ were added and heated at $100^{\circ} \mathrm{C}$ for $10 \mathrm{~min}$ in order to get light green colour solution. The prepared coloured solutions were cooled to room temperature, and finally the volume was made up to $10 \mathrm{~mL}$ using DMF and measured at $706 \mathrm{~nm}$ using a UVVisible spectrophotometer.

(2) Sample Solutions. Twenty tablets of cisplatin hydrochloride were used. The tablets were weighed and triturated, and the contents were thoroughly mixed. The mass equivalent to $150 \mathrm{mg}$ of cisplatin was weighed into a $250 \mathrm{~mL}$ volumetric flask, and phosphate buffer $\mathrm{pH} 6.8$ was added to make up the volume. Appropriate dilutions were made using $1 \mathrm{~mL}$ of $1.4 \mathrm{mg} / \mathrm{mL}$ of OPDA solution and $2 \mathrm{~mL}$ of phosphate buffer $\mathrm{pH} 6.8$ and heated at $100^{\circ} \mathrm{C}$ for $10 \mathrm{~min}$ in order to get light green colour solution. The prepared coloured solutions were cooled to room temperature, and finally the volume was made up to $10 \mathrm{~mL}$ using DMF.

(3) Stability of Cisplatin in Solution. The stability of cisplatin hydrochloride standard stock solution in a mixture of $1.4 \mathrm{mg} / \mathrm{mL}$ of OPDA solution, phosphate buffer $\mathrm{pH} 6.8$, and DMF at a concentration of $0.8 \mu \mathrm{g} / \mathrm{mL}$ was investigated at different time intervals using the experimental conditions.

\subsubsection{Validation of the Developed Method}

(1) Linearity and Range. Linearity of the curve in the concentration range had been assessed by calibration curve using solutions of $0.4,0.6,0.8,1.0,1.2$, and $1.4 \mu \mathrm{g} / \mathrm{mL}$, respectively. Measurements were taken on samples prepared on 3 consecutive days $(n=3)$. The values are reported as the mean \pm

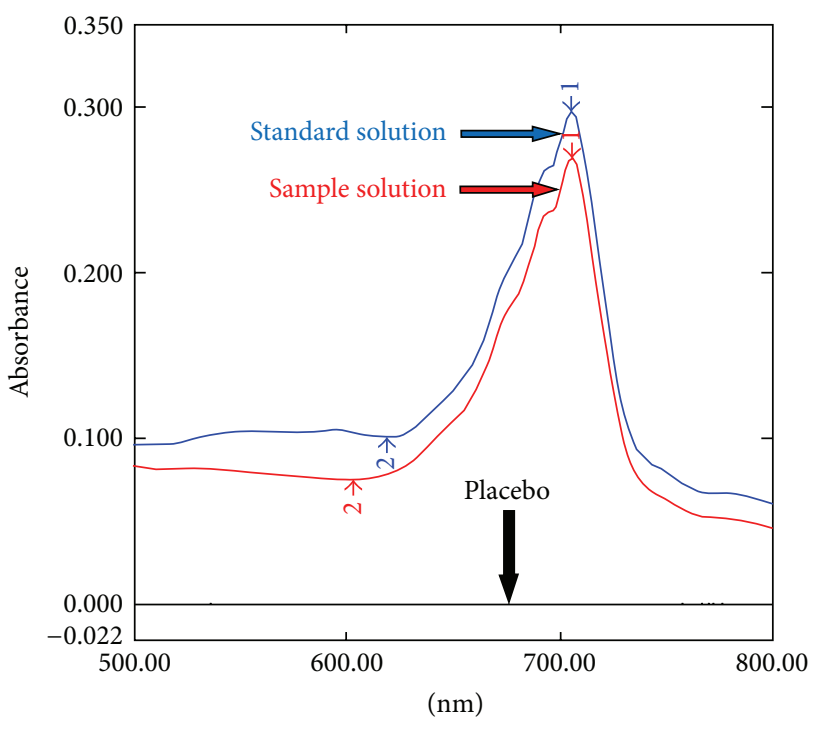

FIGURE 4: Absorption spectra of cisplatin hydrochloride working standard solution, sample solution, and placebo solution.

confidence interval of the calibration curves. The data was analyzed at a wavelength of $706 \mathrm{~nm}$. Evaluation parameters such as the correlation coefficient were calculated and are presented.

(2) Specificity Studies. Specificity was evaluated by an analysis of the visible spectrum of placebo solutions, cisplatin hydrochloride working standard solution, and cisplatin hydrochloride sample solution at concentration of $0.8 \mu \mathrm{g} / \mathrm{mL}$. The placebo solution was prepared with the same composition as the formulation without the addition of cisplatin hydrochloride and treated in the same manner as the commercial sample solution and the reference solution. The solution was filtered through 0.45 micron membrane filter and then subjected for UV analysis. The results of specificity studies are shown in Figure 4.

(3) Accuracy. The accuracy of the method was determined by measuring the reference standard recovery in triplicate at three levels, $50 \%, 100 \%$, and $150 \%$ of the method concentration $(0.8 \mu \mathrm{g} / \mathrm{mL})$. A standard stock solution $100 \mu \mathrm{g} / \mathrm{mL}$ of cisplatin was prepared as described in Section 2.2.2(1). In volumetric flasks of $100 \mathrm{~mL}$, aliquots of $0.4,0.8$, and $1.2 \mathrm{~mL}$ of this solution (which would yield concentrations of 0.4 , 0.8 , and $1.2 \mu \mathrm{g} / \mathrm{mL}$, resp.) were combined with $0.134 \mathrm{~mL}$ of the $600 \mu \mathrm{g} / \mathrm{mL}$ sample solution from Section 2.2.2(2) (this would yield a concentration of $0.8 \mu \mathrm{g} / \mathrm{mL}$ ). Dilutions were made using $1 \mathrm{~mL}$ of $1.4 \mathrm{mg} / \mathrm{mL}$ of OPDA solution and $2 \mathrm{~mL}$ of phosphate buffer $\mathrm{pH} 6.8$ and heated at $100^{\circ} \mathrm{C}$ for $10 \mathrm{~min}$ in order to get light green colour solution. The prepared colored solutions were cooled to room temperature, and finally the volume was made up to $10 \mathrm{~mL}$ using DMF. Thus the final concentrations were $1.2,1.6$ and $2.0 \mu \mathrm{g} / \mathrm{mL}$, which correspond to 50,100 and $150 \%$ of the target concentration, respectively. The mean recoveries of cisplatin $(150 \mathrm{mg})$, expressed in terms 
TABLE 1: Stability of the cisplatin hydrochloride stock standard solution at a concentration of $0.8 \mu \mathrm{g} / \mathrm{mL}$ in mixture of $1.4 \mathrm{mg} / \mathrm{mL}$ of OPDA solution, phosphate buffer $\mathrm{pH}$ 6.8, and DMF.

\begin{tabular}{ccccccccc}
\hline & $0 \mathrm{~h}$ & $1 \mathrm{~h}$ & $5 \mathrm{~h}$ & $12 \mathrm{~h}$ & $24 \mathrm{~h}$ & 1 week & Mean & R.S.D.\% \\
\hline \multirow{3}{*}{ Responses at 706 nm } & 0.176 & 0.178 & 0.170 & 0.179 & 0.175 & 0.175 & 0.175 & 1.79 \\
& 0.178 & 0.177 & 0.175 & 0.178 & 0.176 & 0.172 & 0.176 & 1.30 \\
& 0.174 & 0.175 & 0.172 & 0.176 & 0.172 & 0.170 & 0.173 & 1.29 \\
\hline
\end{tabular}

of the percentage recovery and relative standard deviation (\%R.S.D.), were determined.

(4) Precision. Precision was evaluated with respect to both repeatability and intermediate precision. Repeatability was tested by seven determinations at three levels, 50\%, $100 \%$, and $150 \%$ of the method concentration $(0.8 \mu \mathrm{g} / \mathrm{mL})$ on the same day and under the same experimental conditions. Intermediate precision was evaluated by performing the analysis on three different days (interday) on the same levels as mentioned above and by the three analysts performing the analysis in the same laboratory and under the same experimental conditions (between analyst). Seven replicates at concentrations of $0.4,0.8$, and $1.2 \mu \mathrm{g} / \mathrm{mL}$ were prepared and assayed at $706 \mathrm{~nm}$. The percentage of relative standard deviation (R.S.D.) of the analytical responses was calculated.

(5) Robustness. The robustness of analytical method is measure of its ability to remain unaffected by small changes. In the present study robustness has been calculated by varying the $\mathrm{pH}$ and taking the absorbance at $\mathrm{pH} 6.6, \mathrm{pH} 6.8$ and $\mathrm{pH} 7.0$ of the sample solution (cisplatin hydrochloride $150 \mathrm{mg}$ ). Moreover, the robustness of the method was determined by analyzing a change of $2 \mathrm{~nm}$ in the wavelength of analysis. Seven replicates of the working standard solution and sample solution were prepared at the same concentration $(0.8 \mu \mathrm{g} / \mathrm{mL})$, and the assays were carried out at 704,706 , and $708 \mathrm{~nm}$. The percentage relative standard deviation (R.S.D.) of the quantitation of cisplatin hydrochloride in the tablets was calculated.

(6) Limit of Detection (LOD) and Limit of Quantification (LOQ). Estimation of LOD and LOQ was determined by standard deviation of response $(\sigma)$ and slope of calibration curve $(S)$. Standard deviation of $Y$ intercepts of regression line was used as standard deviation. Equations (1) and (2) for LOD and LOQ, respectively, are as follows:

$$
\begin{aligned}
& \mathrm{LOD}=\frac{3.3 \sigma}{S}, \\
& \mathrm{LOQ}=\frac{10 \sigma}{S} .
\end{aligned}
$$

\subsubsection{Application of Validated Method to Assay and Dissolu- tion Studies of Cisplatin Hydrochloride Tablets}

(1) Assay of Cisplatin Hydrochloride Tablets. The validated UV-spectrometric method was applied to cisplatin hydrochloride quantitation of the (cisplatin hydrochloride tablets
$150 \mathrm{mg}$ ). The results were obtained by comparing the sample spectrophotometric measurements $(n=7)$ with those obtained from the cisplatin hydrochloride standard solutions $(n=7)$ at the same concentration levels.

(2) Dissolution Studies. The dissolution study of cisplatin hydrochloride tablets $(150 \mathrm{mg}$ ) was carried out in $900 \mathrm{~mL}$ phosphate buffer pH 6.8 at $50 \mathrm{rpm}$. From the dissolution medium, $5 \mathrm{~mL}$ samples were withdrawn at $0.25,0.5,1,2,3,4,6,9$, and $12 \mathrm{~h}$, respectively. From this, $1 \mathrm{~mL}$ of solution was pipetted out, and diluted to $10 \mathrm{~mL}$ by using phosphate buffer $\mathrm{pH} 6.8$. Again from the diluted solution, $1 \mathrm{~mL}$ solution was pipetted out and dilutions were made by using $1 \mathrm{~mL}$ of $1.4 \mathrm{mg} / \mathrm{mL}$ of OPDA solution and $2 \mathrm{~mL}$ of phosphate buffer $\mathrm{pH} 6.8$ and heated at $100^{\circ} \mathrm{C}$ for $10 \mathrm{~min}$ in order to get light green colour solution. The prepared coloured solutions were cooled to room temperature, and finally the volume was made up to $10 \mathrm{~mL}$ using DMF which were measured at $706 \mathrm{~nm}$ using a UV-Visible spectrophotometer. The study was conducted for 6 tablets, and the mean \% cumulative drug release was recorded $(n=6)$.

\section{Results and Discussions}

3.1. Method Development. The reported methods for the determination of cisplatin were complex and time consuming. Moreover, some methods were developed on sophisticated instruments like HPLC which have higher costs. Precolumn derivatization of cisplatin hydrochloride (as it lacks chromophore) followed by HPLC analysis makes the process tedious and expensive. In this paper, phosphate buffer $\mathrm{pH}$ 6.8, OPDA, and DMF were chosen to obtain an inexpensive, simple, and environment friendly colorimetric method for the quantification of cisplatin hydrochloride in tablets.

3.2. Stability of Cisplatin in Solution. The results from the stability study indicated that the cisplatin hydrochloride stock standard solution was stable at room temperature for at least one week (Table 1).

3.3. Method Validation. After the method development, the analytical method was validated according to ICH recommendations.

3.3.1. Linearity and Range. The analytical curves, obtained on three consecutive days $(n=3)$ by plotting the mean of absorbance at $706 \mathrm{~nm}$ against the concentration, were found to be linear in the 0.4 to $1.4 \mu \mathrm{g} / \mathrm{mL}$ range and yielded 
TABLE 2: Linearity parameters for the determination of cisplatin hydrochloride.

\begin{tabular}{lc}
\hline Parameters & Results \\
\hline Linearity range $(\mu \mathrm{g} / \mathrm{mL})$ & 0.4 to 1.4 \\
Slope & 0.2165 \\
Intercept & 0.0008 \\
Correlation coefficient $(r)$ & 0.9999 \\
\hline
\end{tabular}

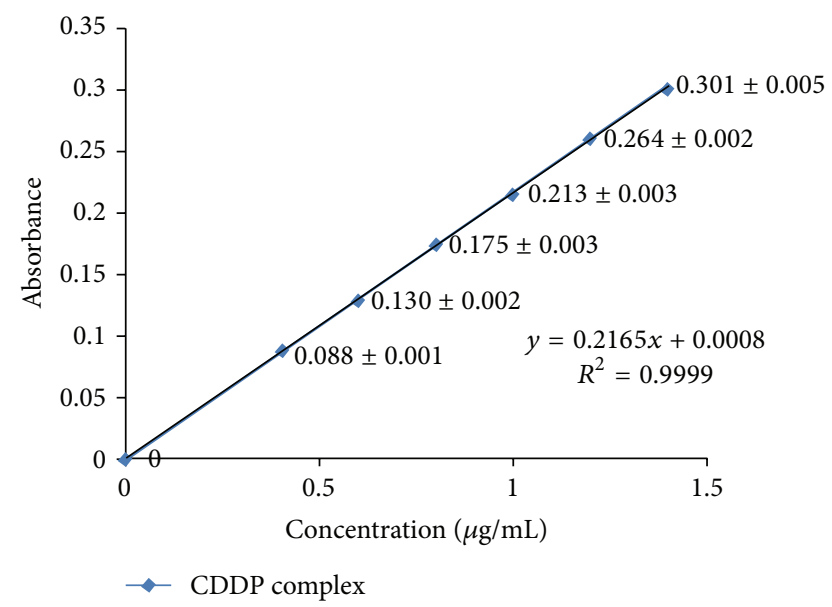

FIGURE 5: Calibration curve of cisplatin hydrochloride in a mixture of $1.4 \mathrm{mg} / \mathrm{mL}$ of OPDA solution, phosphate buffer $\mathrm{pH} 6.8$, and DMF.

a correlation coefficient $(r)$ of 0.9994 shown in Table 2 and Figure 5.

3.3.2. Selectivity. The spectra analysis showed that the formulation excipients of the pharmaceutical tablet product containing cisplatin hydrochloride tablets $150 \mathrm{mg}$ did not interfere with the developed colorimetric method as shown in Figure 4. The spectrum showed that the placebo did not have absorbance in the wavelength used in this method.

3.3.3. Accuracy. The accuracy of the proposed method was assessed by determining the average recoveries of samples using the standard addition method. As shown in Table 3, the mean percentage recovery of cisplatin hydrochloride tablets (150 mg) was $99.59 \%$, and the \% relative standard deviation (\%R.S.D.) was $0.76 \%$. The results were in accordance with fixed limits from $98.0 \%$ to $102.0 \%$, indicating the suitability of the developed method in quantifying the concentration of cisplatin hydrochloride in tablets. The accuracy value of the current method was found to beexcellent should be written as be excellent.

3.3.4. Precision. The precision, evaluated as the repeatability of the analytical method, was studied by calculating the $\%$ relative standard deviation for the seven determinations of the $0.4,0.8$, and $1.2 \mu \mathrm{g} / \mathrm{mL}$ working standard solution performed on the same day and under the same experimental conditions. The obtained \%R.S.D. value was less than $2.5 \%$.

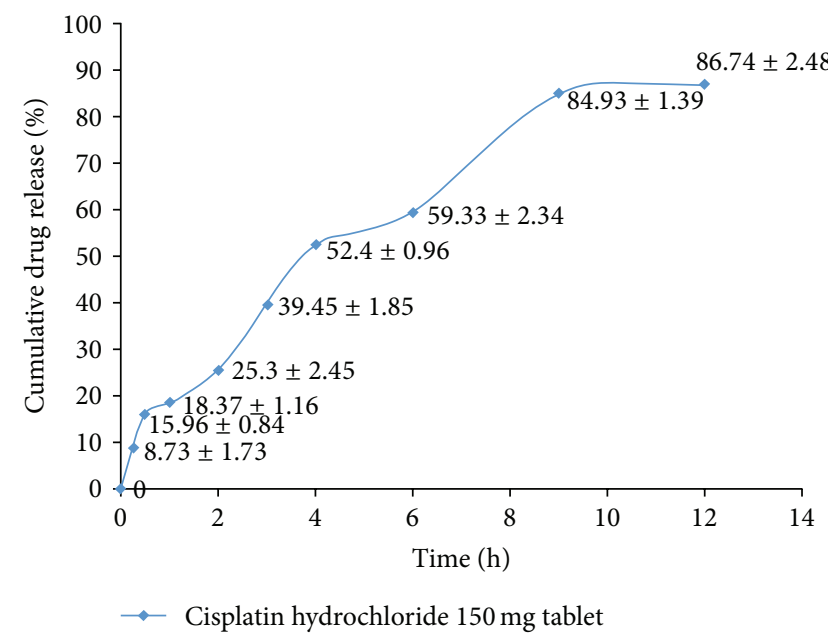

FIGURE 6: Mean \% cumulative drug release profile of cisplatin hydrochloride $150 \mathrm{mg}$ tablets $(n=6)$.

The intermediate precision was assessed by analyzing a sample of the pharmaceutical formulation on 3 different days (interday precision) and by analyzing the samples with three analysts (between-analysts precision). The \%R.S.D. values were less than $2.5 \%$ confirming that the method is sufficiently precise (Table 4).

3.3.5. Robustness. The robustness was found reliable, as determined by \%R.S.D. $(<2 \%)$. It was observed that the constancy of the absorbance with deliberative changes in the experimental parameter of wavelength resulted in a \%R.S.D. of 0.81 and change in $\mathrm{pH}$ resulted in a \%R.S.D. of 0.72 (Table 5). The minor changes that occurred during the analysis did not affect the absorbance intensity of the samples.

3.3.6. Limits of Detection and Quantification. LOD and LOQ values were found to be $0.038 \pm 0.056$ and $0.116 \pm$ $0.058 \mu \mathrm{g} / \mathrm{mL}$, respectively, for cisplatin hydrochloride tablets $(150 \mathrm{mg})$. These results demonstrated that the analyses were being performed in a region above the quantification limit value.

3.3.7. Assay of Cisplatin Hydrochloride Tablets. The validated method was applied to the determination of cisplatin hydrochloride in tablets. Three samples of cisplatin hydrochloride tablets $(150 \mathrm{mg})$ were analyzed. The results, expressed as the percentage drug as related to the content label claim, are shown in Table 6 . The results showed that the percentage drug is in accordance with the Indian, British, and United States Pharmacopoeias, which permit cisplatin hydrochloride in tablets to be in a range from 92.5 to $110.0 \%$ of the content label claim.

3.3.8. Dissolution Studies. An analytical method should be developed in such a way that it should be able to evaluate all the parameters quantitatively during the early product 
TABLE 3: Method accuracy results for cisplatin hydrochloride tablets.

\begin{tabular}{|c|c|c|c|c|c|c|}
\hline $\begin{array}{l}\text { Sample }(\mu \mathrm{g} / \mathrm{mL}) \\
\text { cisplatin hydrochloride }\end{array}$ & $\begin{array}{c}\text { Reference standard } \\
\text { concentration } \\
\text { added }(\mu \mathrm{g} / \mathrm{mL})\end{array}$ & $\begin{array}{c}\text { Total } \\
\text { concentration of } \\
\text { solution }(\mu \mathrm{g} / \mathrm{mL})\end{array}$ & $\begin{array}{c}\text { Concentration } \\
\text { of drug found } \\
(\mu \mathrm{g} / \mathrm{mL})\end{array}$ & Recovery (\%) & $\begin{array}{l}\text { R.S.D. }(\%) \\
\quad(n=3)\end{array}$ & Mean recovery $(\%)$ \\
\hline \multirow{3}{*}{0.8} & 0.4 & 1.2 & 1.19 & 99.16 & 0.16 & \multirow{3}{*}{99.98} \\
\hline & 0.8 & 1.6 & 1.61 & 100.62 & 1.2 & \\
\hline & 1.2 & 2.0 & 2.0 & 100.18 & 0.92 & \\
\hline
\end{tabular}

TABLE 4: Method precision results for cisplatin hydrochloride tablets.

\begin{tabular}{|c|c|c|c|c|c|c|c|c|c|}
\hline & \multirow{2}{*}{ Concentration $(\mu \mathrm{g} / \mathrm{mL})$} & \multicolumn{7}{|c|}{ Analytical response } & \multirow{2}{*}{ R.S.D.\% } \\
\hline & & 1 & 2 & 3 & 4 & 5 & 6 & 7 & \\
\hline \multirow{3}{*}{ Repeatability } & 0.4 & 0.094 & 0.093 & 0.090 & 0.091 & 0.094 & 0.092 & 0.091 & 1.71 \\
\hline & 0.8 & 0.179 & 0.174 & 0.182 & 0.184 & 0.182 & 0.181 & 0.180 & 1.77 \\
\hline & 1.2 & 0.272 & 0.271 & 0.279 & 0.265 & 0.271 & 0.273 & 0.272 & 1.51 \\
\hline \multicolumn{10}{|c|}{ Intermediate precision } \\
\hline \multirow{3}{*}{ Day 1} & 0.4 & 0.096 & 0.094 & 0.092 & 0.096 & 0.094 & 0.091 & 0.092 & 2.12 \\
\hline & 0.8 & 0.182 & 0.184 & 0.178 & 0.182 & 0.174 & 0.179 & 0.176 & 2.00 \\
\hline & 1.2 & 0.265 & 0.268 & 0.270 & 0.279 & 0.273 & 0.272 & 0.273 & 1.63 \\
\hline \multirow{3}{*}{ Day 2} & 0.4 & 0.094 & 0.096 & 0.095 & 0.095 & 0.091 & 0.096 & 0.092 & 2.07 \\
\hline & 0.8 & 0.182 & 0.181 & 0.182 & 0.182 & 0.186 & 0.183 & 0.184 & 0.92 \\
\hline & 1.2 & 0.254 & 0.252 & 0.256 & 0.258 & 0.259 & 0.252 & 0.260 & 1.29 \\
\hline \multirow{3}{*}{ Day 3} & 0.4 & 0.089 & 0.087 & 0.086 & 0.089 & 0.086 & 0.085 & 0.089 & 1.95 \\
\hline & 0.8 & 0.179 & 0.182 & 0.180 & 0.184 & 0.181 & 0.182 & 0.185 & 1.16 \\
\hline & 1.2 & 0.256 & 0.254 & 0.250 & 0.256 & 0.252 & 0.254 & 0.250 & 1.01 \\
\hline \multirow{3}{*}{ Analyst A } & 0.4 & 0.092 & 0.095 & 0.094 & 0.091 & 0.094 & 0.092 & 0.093 & 1.52 \\
\hline & 0.8 & 0.185 & 0.184 & 0.179 & 0.184 & 0.182 & 0.181 & 0.179 & 1.35 \\
\hline & 1.2 & 0.268 & 0.273 & 0.275 & 0.272 & 0.270 & 0.272 & 0.269 & 0.90 \\
\hline \multirow{3}{*}{ Analyst B } & 0.4 & 0.091 & 0.094 & 0.092 & 0.094 & 0.095 & 0.092 & 0.090 & 1.96 \\
\hline & 0.8 & 0.176 & 0.174 & 0.172 & 0.175 & 0.178 & 0.174 & 0.176 & 1.09 \\
\hline & 1.2 & 0.269 & 0.271 & 0.272 & 0.272 & 0.275 & 0.277 & 0.268 & 1.16 \\
\hline \multirow{3}{*}{ Analyst C } & 0.4 & 0.094 & 0.096 & 0.095 & 0.091 & 0.097 & 0.094 & 0.096 & 2.09 \\
\hline & 0.8 & 0.186 & 0.181 & 0.182 & 0.184 & 0.182 & 0.187 & 0.189 & 1.62 \\
\hline & 1.2 & 0.262 & 0.256 & 0.258 & 0.256 & 0.257 & 0.262 & 0.254 & 1.19 \\
\hline
\end{tabular}

development stage till the final product release. Dissolution studies play a major role in order to provide drug release testing during early preformulation studies as well as in vitro-in vivo correlation of the compound during the bioavailability studies and clinical trials. Therefore dissolution studies were conducted in order to check the feasibility of this developed and validated method for quantification of dissolution samples. The mean \% cumulative drug release was found to be $86.74 \%$ after $12 \mathrm{~h}$. The dissolution profile of cisplatin hydrochloride tablets $(150 \mathrm{mg}$ ) is shown in Figure 6. This showed that the developed method can be successfully applied to dissolution studies.

UV, UV-VIS, and derivative spectrophotometry are broadly used techniques to quantify antibiotics and other drugs because they are cost effective and simple and do not require time-consuming sample preparation compared to other techniques. Moreover, UV-Visible spectrophotometry produces very low amount of residues and solvents, which is an important ecological aspect as per regulatory point of view and currently discussed in routine laboratory analysis. Because of these reasons and the careful validation of this method, this technique can be recommended for the routine laboratory analysis of the cisplatin hydrochloride in tablets.

\section{Conclusion}

The validated analytical method for quantitative determination of cisplatin hydrochloride in tablets has the advantages of simplicity, speed, low-cost conditions, and a lack of polluting reagents. All validation parameters were found to be highly satisfactory, including linearity, accuracy, precision, selectivity, robustness, and adequate detection and quantitation limits. The validated method could be a good alternative for routine quality control of cisplatin hydrochloride by the pharmaceutical industries and quality control laboratories. 
TABLE 5: Robustness test results.

\begin{tabular}{|c|c|c|c|c|c|}
\hline Sample & $\mathrm{pH}$ & Wavelength (nm) & Content $(\mathrm{mg})^{\mathrm{a}}$ & Content $(\%)^{\mathrm{a}}$ & R.S.D. (\%) \\
\hline \multirow{6}{*}{ Cisplatin hydrochloride $150 \mathrm{mg}$ tablets } & 6.6 & & 152.37 & 101.58 & \multirow{3}{*}{0.72} \\
\hline & 6.8 & NA & 149.07 & 99.38 & \\
\hline & 7.0 & & 150.43 & 100.28 & \\
\hline & & 704 & 152.03 & 101.35 & \multirow{3}{*}{0.81} \\
\hline & ${ }^{*} \mathrm{NA}$ & 706 & 148.75 & 99.16 & \\
\hline & & 708 & 151.72 & 101.14 & \\
\hline
\end{tabular}

${ }^{\mathrm{a}}$ Mean of seven replicates; ${ }^{*} \mathrm{NA}$ : not applicable.

TABLE 6: Assay of cisplatin hydrochloride tablets (cisplatin hydrochloride $150 \mathrm{mg}$ tablets) samples $\mathrm{A}, \mathrm{B}$, and C.

\begin{tabular}{lccc}
\hline Sample & Content $(\mathrm{mg})$ & Content $(\%)$ & R.S.D. (\%) \\
\hline 1 & 152.05 & 101.36 & \\
2 & 149.10 & 99.4 & 1.26 \\
3 & 148.50 & 99.0 & \\
\hline
\end{tabular}

\section{Acknowledgments}

The authors are grateful to Mr. Ashok Mittal, Chancellor, Lovely Professional University, India for providing facilities to carry out the aforementioned research. Theye also owe their thanks to Astron Research Limited, Gujarat, India, for providing the gift samples of cisplatin hydrochloride.

\section{References}

[1] B. Rosenberg, L. Van Camp, E. B. Grimley, and A. J. Thomson, "The inhibition of growth or cell division in Escherichia coli by different ionic species of platinum(IV) complexes," The Journal of Biological Chemistry, vol. 242, no. 6, pp. 1347-1352, 1967.

[2] M. E. Bosch, A. J. R. Sánchez, F. S. Rojas, and C. B. Ojeda, "Analytical methodologies for the determination of cisplatin," Journal of Pharmaceutical and Biomedical Analysis, vol. 47, no. 3, pp. 451-459, 2008.

[3] K. Inagaki, S. Yonehara, and Y. Kidani, "Direct determination of cis-dichlorodiammineplatinum(II) in urine by derivative spectroscopy," Chemical and Pharmaceutical Bulletin, vol. 33, no. 8, pp. 3369-3374, 1985.

[4] B. Anilanmert, G. Yalçin, F. Ariöz, and E. Dölen, "The spectrophotometric determination of cisplatin in urine, using ophenylenediamine as derivatizing agent," Analytical Letters, vol. 34, no. 1, pp. 113-123, 2001.

[5] M. Y. Khuhawar, G. M. Arain, and A. Shah, "Spectrophotometry determination of platinum (II) from platinum based cisplatin and carboplatin anticancer injections," The Nucleus, vol. 41, pp. 59-62, 2004.

[6] E. D. Golla and G. H. Ayres, "Spectrophotometric determination of platinum with o-phenylenediamine," Talanta, vol. 20, no. 2, pp. 199-210, 1973.

[7] R. A. Baumann, C. Gooijer, and N. H. Velthorst, "Quantitative determination of cisplatin in body fluids by liquid chromatography with quenched phosphorescence detection," Journal of Pharmaceutical and Biomedical Analysis, vol. 5, no. 2, pp. 165$170,1987$.

[8] M. Verschraagen, K. Van der Born, T. H. U. Zwiers, and W. J. F. Van der Vijgh, "Simultaneous determination of intact cisplatin and its metabolite monohydrated cisplatin in human plasma," Journal of Chromatography B, vol. 772, no. 2, pp. 273-281, 2002.

[9] J. M. M. Terwogt, M. M. Tibben, H. Welbank, J. H. M. Schellens, and J. H. Beijnen, "Validated method for the determination of platinum from a liposomal source (SPI-77) in human plasma using graphite furnace Zeeman atomic absorption spectrometry," Fresenius' Journal of Analytical Chemistry, vol. 366, no. 3, pp. 298-302, 2000.

[10] R. Raghavan and J. A. Mulligan, "Low-level (PPB) determination of cisplatin in cleaning validation (rinse water) samples. I. An atomic absorption spectrophotometric method," Drug Development and Industrial Pharmacy, vol. 26, no. 4, pp. 423428, 2000.

[11] J. Petrlova, D. Potesil, J. Zehnalek et al., "Cisplatin electrochemical biosensor," Electrochimica Acta, vol. 51, no. 24, pp. 5169-5173, 2006.

[12] M. El-Khateeb, T. G. Appleton, B. G. Charles, and L. R. Gahan, "Development of HPLC conditions for valid determination of hydrolysis products of cisplatin," Journal of Pharmaceutical Sciences, vol. 88, no. 3, pp. 319-326, 1999.

[13] R. Kizu, S.-I. Higashi, and M. Miyazaki, "A method for determining cis-dichlorodiammineplatinum(II) in plasma and urine by high performance liquid chromatography with direct ultraviolet detection," Chemical and Pharmaceutical Bulletin, vol. 33, no. 10, pp. 4614-4617, 1985.

[14] H. H. Farrish, P.-H. Hsyu, J. F. Pritchard, K. R. Brouwer, and J. Jarrett, "Validation of a liquid chromatography post-column derivatization assay for the determination of cisplatin in plasma," Journal of Pharmaceutical and Biomedical Analysis, vol. 12, no. 2, pp. 265-271, 1994.

[15] A. Andersson and H. Ehrsson, "Determination of cisplatin and cis-diammineaquachloroplatinum(II) ion by liquid chromatography using post-column derivatization with diethyldithiocarbamate," Journal of Chromatography B, vol. 652, no. 2, pp. 203210, 1994.

[16] A. Andersson, J. Fagerberg, R. Lewensohn, and H. Ehrsson, "Pharmacokinetics of cisplatin and its monohydrated complex in humans," Journal of Pharmaceutical Sciences, vol. 85, no. 8, pp. 824-827, 1996.

[17] K. Hanada, N. Nagai, and H. Ogata, "Quantitative determination of unchanged cisplatin in rat kidney and liver by highperformance liquid chromatography," Journal of Chromatography B, vol. 663, no. 1, pp. 181-186, 1995.

[18] R. Kizu, T. Yamamoto, T. Yokoyama, M. Tanaka, and M. Miyazaki, "A sensitive postcolunan derivatization/UV detection system for HPLC determination of antitumor divalent and quadrivalent platinum complexes," Chemical and Pharmaceutical Bulletin, vol. 43, no. 1, pp. 108-114, 1995. 
[19] M. Y. Khuhawar, S. N. Lanjwani, and S. A. Memon, "Highperformance liquid chromatographic determination of cisplatin as platinum(II) in a pharmaceutical preparation and blood samples of cancer patients," Journal of Chromatography B, vol. 693, no. 1, pp. 175-179, 1997.

[20] S. N. Lanjwani, R. Zhu, M. Y. Khuhawar, and Z. Ding, "High performance liquid chromatographic determination of platinum in blood and urine samples of cancer patients after administration of cisplatin drug using solvent extraction and N,N'bis(salicylidene)-1,2-propanediamine as complexation reagent," Journal of Pharmaceutical and Biomedical Analysis, vol. 40, no. 4, pp. 833-839, 2006.

[21] M. Macka, J. Borak, and F. Kiss, "Separation of some platinum(II) complexes by ionic strength gradient on a solventgenerated ion-exchange sorbent," Journal of Chromatography, vol. 586, no. 2, pp. 291-295, 1991. 

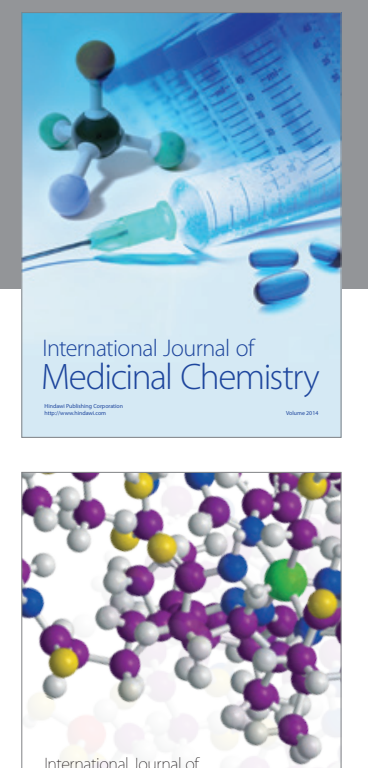

\section{Carbohydrate} Chemistry

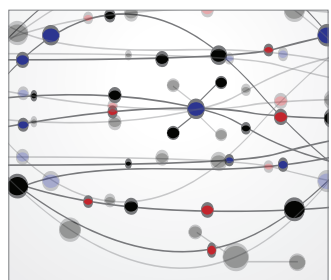

The Scientific World Journal
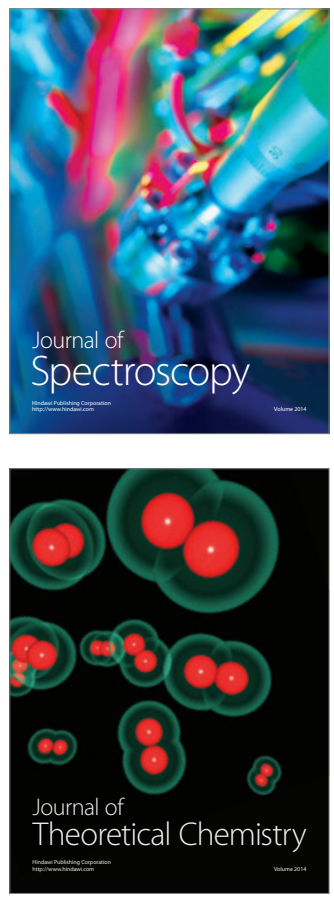
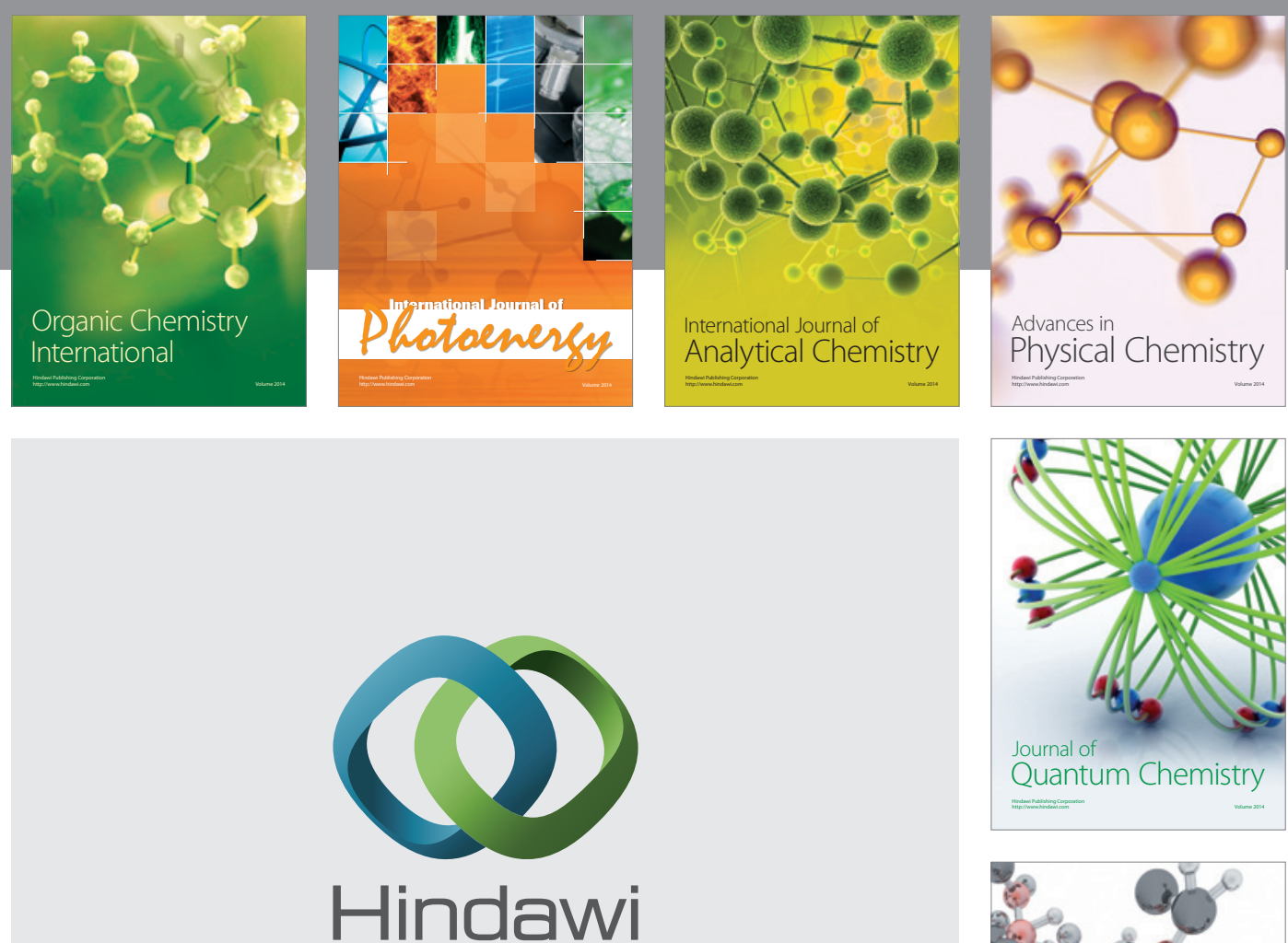

Submit your manuscripts at

http://www.hindawi.com

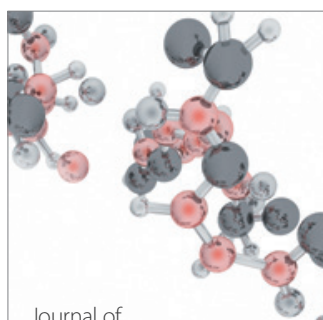

Analytical Methods

in Chemistry

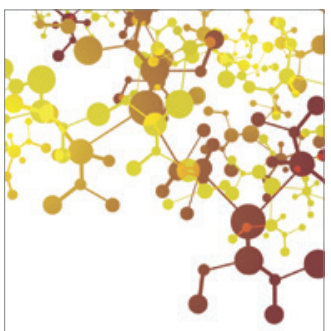

Journal of

Applied Chemistry

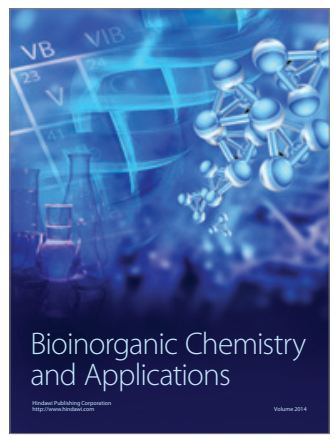

Inorganic Chemistry
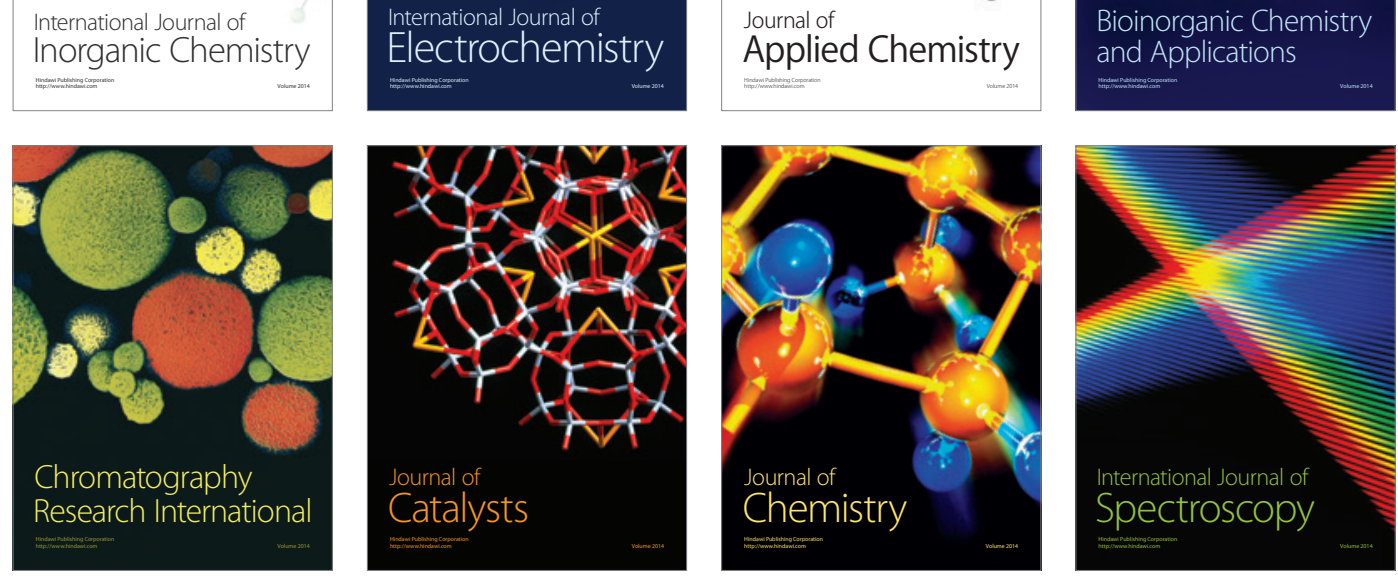